\title{
Investigation on Joining Divergent Geometric Profiles using 20KHz Ultrasonic Sound Waves
}

\author{
J.Pradeep Kumar ${ }^{1}$, M.Sambath Kumar ${ }^{1}$, D.Nishandh ${ }^{1}$, K.B.Sandeep Kumar ${ }^{1}$, P.Sathish \\ Kumar $^{1}$ \\ \{jpk.prod@psgtech.ac.in, sambath22091993@gmail.com,nishandhds@gmail.com, \\ san17593cessna@gmail.com, psathi25@gmail.com \}
}

Department of Production Engineering, PSG College of Technology, Coimbatore - $641004^{1}$

\begin{abstract}
In the modern scenario of solid-state welding, Ultrasonic metal welding (USMW) has emerged as one of the successful and efficient method of joining metal specimens with dissimilar profiles (cylindrical - flat). As the methods and procedures involved in repairing flaws are not cost effective, many industries require a systematic approach to forecast weld strength before manufacturing the weld joints. This study is carried out to develop a mathematical model for predicting the weld strength using response surface method. Experiments are conducted based on response surface design matrix comprising of five factors such as the weld time, amplitude, weld pressure, sheet thickness and wire diameter and the weld strength of each experimental trials evaluated in terms of T-peel load are measured. Also, a feed forward back propagation artificial neural network with supervised training has been developed to predict the T-peel load and it tends to be consistent throughout the entire range values.
\end{abstract}

Keywords: Ultrasonic metal welding, Response surface methodology, Artificial neural network.

\section{Introduction}

Ultrasonic Metal Welding (USMW) is a solid-state welding procedure in which identical or dissimilar metallic work parts are bonded together using high-frequency vibrations in plane with the interface while under moderate pressure. When compared to the melting point of the metal, the temperature created between the pieces in USMW is quite low. The procedure can be done in a matter of seconds without affecting the material's qualities.

The quality of weld mainly depends upon the strength and the load it can withstand when applied in practical conditions. Weld failure occurs suddenly, resulting in lost production, part rejection, and customer dissatisfaction. T-peel load generally influences the quality of weld, whereas the T-peel load is influenced by factors such as pressure, amplitude, weld time, sheet thickness and wire diameter. Weld time helps in determining bonding between sheet and wire, better bonding leads to increased T-peel load, and pressure also helps in maintaining a constant contact pressure between sheet and wire, and amplitude which determines the frequency of vibration of horn which helps in penetrating wire into the sheet. 
Chen Y C et al. (2012) discovered that ultrasonic metal welding utilizes significantly less energy than traditional resistance spot welding. Bonding is commonly achieved in ultrasonic metal welding at a low temperature. In ultrasonic metal welding bonding of metal molecules is attained at low temperature $\left(<300^{\circ} \mathrm{C}\right.$ in short weld cycle typically for $\left.0.5 \mathrm{sec}\right)$. Annoni M et al (2011) evaluated the effects of high frequency shear vibrations, typically $20 \mathrm{kHz}$, on the removal of oxide and contaminated layers, as well as the production of heat by shear deformation. Softening occurs as the temperature rises and acoustic energy is absorbed, lowering the material's yield strength. As a result, metals come into touch with one another, causing adhesion and inter diffusion at the interface. Hu S I et al (1996) examined that weld quality or bond strength of ultrasonic metal welding specimen is quantified by the T-peel test as used in resistance spot welding. The joining technique avoided frequent concerns related with fusion welding, such as rapid intermediate production, evolution of brittle phases, and distortion in weld portions, according to Neppira E A et al (1965).

In many of the earlier works only the process parameters are concerned, whereas the geometric profiles of the specimens are not considered effectively. In this work the combination of both the process parameters and the geometric profiles are taken into consideration.

The influence of process parameters on T-peel load is analyzed using analysis of variance technique (ANOVA). The mathematical model is developed for the process and the validity of the mathematical model was further trained by ANN.

\section{Response Surface Methodology (RSM)}

Simultaneous study of multiple variables can be done using the statistical technique of design of experiments, in which equal number of test conditions is allowed for each individual factor. An efficient plan for conducting the experiments can be obtained using the statistical design of experiments to finally yield objective conclusions.

The Response surface methodology (RSM) is commonly employed for modeling analysis with a final interest of funneling the factors of interest to an objective maximum by following mathematical and statistical techniques. The change in response in different directions is understood according to the design variables. The goal is to proceed quickly and efficiently along a path in order to get a maximum or minimum response that is optimum.

Identifying important process variables, determining their limits, developing the design matrix, conducting experiments according to the design matrix, recording the responses, developing a mathematical model, checking the adequacy of the model developed, and finally analyzing the results are all steps involved in response surface methodology for experimental investigation..

\section{Identification of process variables}

In order to achieve a larger T-peel load, it is critical to identify the optimal process parameters. By carefully selecting the independently controlled process factors, the desired Tpeel load can be attained. Pressure (bar), amplitude (m), weld duration (sec), sheet thickness $(\mathrm{mm})$, and wire diameter $(\mathrm{mm})$ are chosen as factors to conduct out experimental work and 
construct a mathematical model among independently adjustable variables affecting T-peel load. Table 1 lists the factors that were taken into account.

Table 1 Attribution of levels to factors

\begin{tabular}{|l|l|l|l|l|}
\hline \multirow{2}{*}{$\begin{array}{l}\text { Variable } \\
\text { Name }\end{array}$} & \multirow{2}{*}{ Weld Parameters } & \multicolumn{3}{|l|}{ Levels } \\
\cline { 3 - 5 } & & $\mathbf{- 1}$ & $\mathbf{0}$ & $\mathbf{1}$ \\
\hline X1 & Weld Pressure (bar) & 3 & 4 & 5 \\
\hline X2 & Amplitude $(\mu \mathrm{m})$ & 28 & 42.5 & 57 \\
\hline X3 & Weld Time $(\mathrm{sec})$ & 3 & 4 & 5 \\
\hline X4 & $\begin{array}{l}\text { Sheet Thickness }(\mathrm{mm}) \\
\text { - Aluminum }\end{array}$ & 0.1 & 0.2 & 0.3 \\
\hline X5 & $\begin{array}{l}\text { Wire Diameter }(\mathrm{mm})- \\
\text { Aluminum }\end{array}$ & 0.9 & 1.2 & 1.6 \\
\hline
\end{tabular}

The working ranges for all the parameters must be fixed and the design matrix has to be constructed as per Response surface methodology. This is accomplished by running tests in which one of the process variables is changed while the others remain constant.

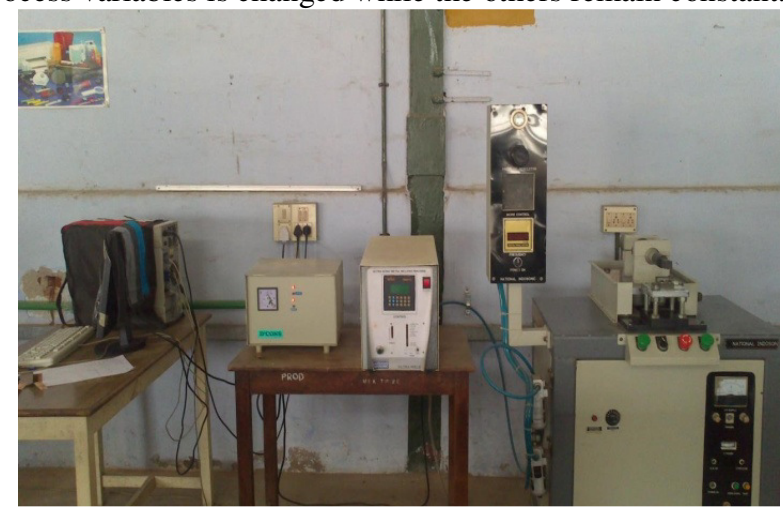

Figure 1 Ultrasonic Metal Welding Machine

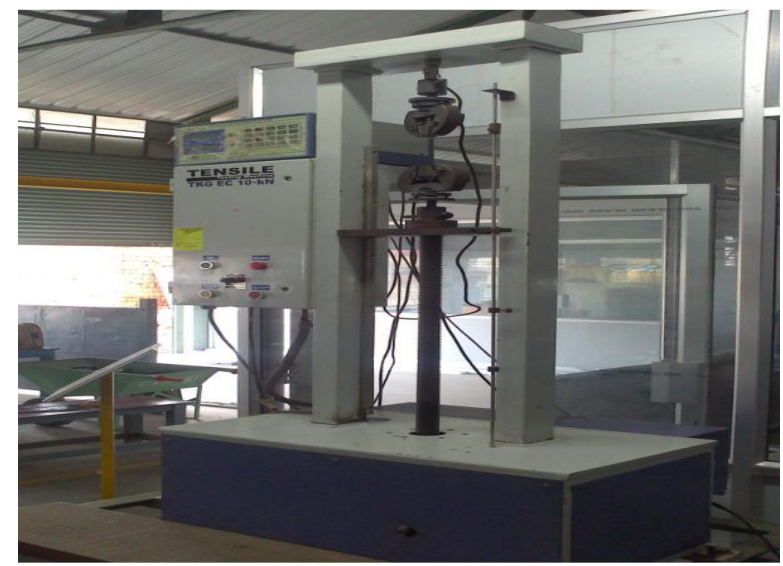


Figure 2 Tensile Testing Machine.

\subsection{Experiment design matrix}

The tests are carried out for all possible combinations of parameter levels, which are listed in Table 2, where rows correspond to different process variables and columns correspond to variable levels, forming the design matrix. A five factor three level central composite design with 32 experiments was chosen as the design matrix for the experiment.

\section{Experimental Details}

The experiments are conducted as per the design matrix and they are performed in the order of run order. The experiments are carried out in USMW setup shown in the Figure 1. Figure 2 depicts the experimental setup for determining the T-peel load. For performing the tensile testing operations the aluminum specimens are prepared according to standard shown in Figure 3. The results of the experiments are shown in the Table 2.

The welded specimens are as shown in Figure 4 and the position of holding of the welded specimens is shown in the Figure 5.

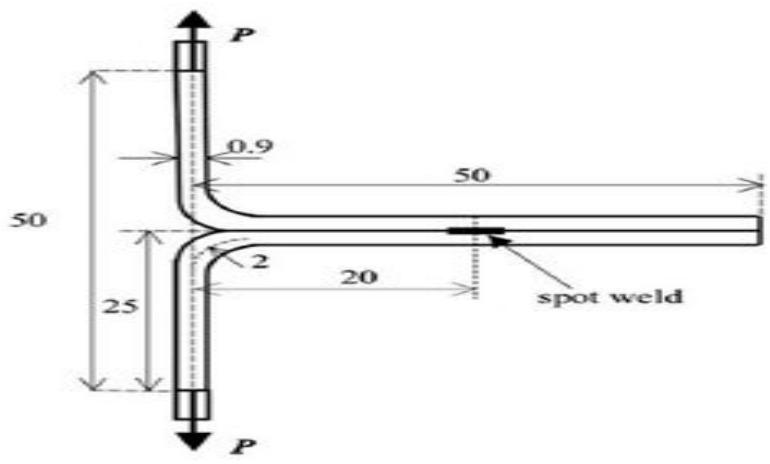

Figure 3 T Peel Specimen

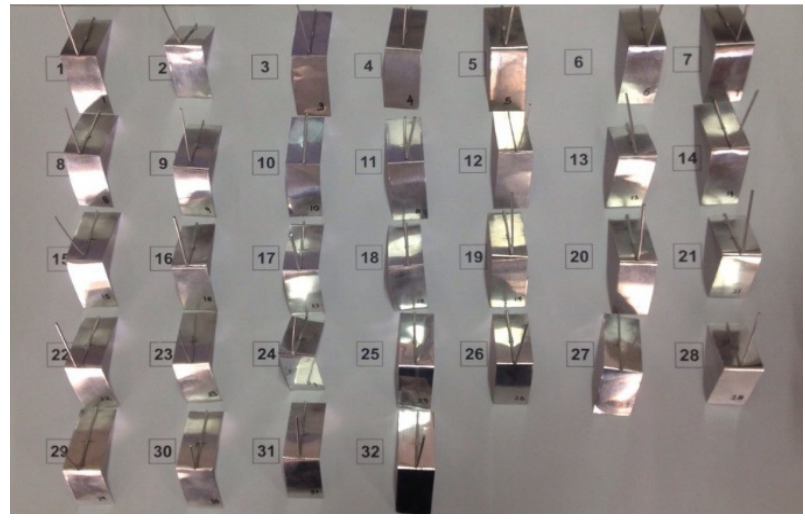


Figure 4 Welded aluminum specimens

Table 2 Comparison of T Peel load values of experimental values, mathematical model and ANN predicted values

\begin{tabular}{|c|c|c|c|c|c|c|c|c|c|c|}
\hline \multirow[b]{2}{*}{$\begin{array}{l}\text { Run } \\
\text { order }\end{array}$} & \multirow[b]{2}{*}{$\mathbf{X 1}$} & \multirow[b]{2}{*}{$\mathbf{X} 2$} & \multirow[b]{2}{*}{$\mathbf{X 3}$} & \multirow[b]{2}{*}{$\mathbf{X} 4$} & \multirow[b]{2}{*}{ X5 } & \multicolumn{5}{|c|}{ T-peel Load in kgf } \\
\hline & & & & & & $\begin{array}{l}\text { Experimental } \\
\text { Results }\end{array}$ & $\begin{array}{l}\text { Mathematical } \\
\text { model } \\
\text { Results }\end{array}$ & Error & $\begin{array}{l}\text { ANN } \\
\text { Results }\end{array}$ & Error \\
\hline 1 & 5 & 57 & 3 & 0.1 & 1.6 & 0.023 & 0.0231 & -0.0001 & 0.028 & -0.005 \\
\hline 2 & 3 & 57 & 3 & 0.1 & 0.9 & 0.01 & 0.0104 & -0.0004 & 0.01 & 0.00 \\
\hline 3 & 3 & 28 & 5 & 0.1 & 0.9 & 0.0105 & 0.0103 & 0.0002 & 0.01008 & 0.00042 \\
\hline 4 & 5 & 28 & 3 & 0.1 & 0.9 & 0.0185 & 0.0187 & -0.0002 & 0.01011 & 0.00839 \\
\hline 5 & 4 & 42.5 & 4 & 0.2 & 1.25 & 0.0535 & 0.0494 & 0.0041 & 0.05105 & 0.00245 \\
\hline 6 & 4 & 42.5 & 4 & 0.2 & 1.25 & 0.047 & 0.0494 & -0.0024 & 0.05105 & -0.00405 \\
\hline 7 & 3 & 28 & 3 & 0.1 & 1.6 & 0.014 & 0.0118 & 0.0022 & 0.01288 & 0.00112 \\
\hline 8 & 4 & 42.5 & 4 & 0.2 & 0.9 & 0.023 & 0.0197 & 0.0033 & 0.02476 & -0.00176 \\
\hline 9 & 4 & 28 & 4 & 0.2 & 1.25 & 0.0475 & 0.0544 & -0.0069 & 0.04657 & 0.00093 \\
\hline 10 & 4 & 42.5 & 4 & 0.2 & 1.6 & 0.055 & 0.062 & -0.007 & 0.06719 & -0.01219 \\
\hline 11 & 3 & 57 & 5 & 0.1 & 1.6 & 0.015 & 0.0148 & 0.0002 & 0.0205 & -0.0055 \\
\hline 12 & 5 & 57 & 5 & 0.3 & 1.6 & 0.057 & 0.0574 & -0.0004 & 0.0586 & -0.0016 \\
\hline 13 & 3 & 42.5 & 4 & 0.2 & 1.25 & 0.042 & 0.0479 & -0.0059 & 0.04314 & -0.00114 \\
\hline 14 & 3 & 28 & 3 & 0.3 & 0.9 & 0.0145 & 0.0132 & 0.0013 & 0.0299 & -0.0154 \\
\hline 15 & 4 & 42.5 & 4 & 0.2 & 1.25 & 0.0535 & 0.0494 & 0.0041 & 0.05105 & 0.00245 \\
\hline 16 & 4 & 42.5 & 5 & 0.2 & 1.25 & 0.0505 & 0.0496 & 0.0009 & 0.05656 & -0.00606 \\
\hline 17 & 3 & 57 & 5 & 0.3 & 0.9 & 0.0145 & 0.0152 & -0.0007 & 0.0314 & -0.0169 \\
\hline 18 & 3 & 28 & 5 & 0.3 & 1.6 & 0.0985 & 0.0966 & 0.0019 & 0.1026 & -0.0041 \\
\hline 19 & 3 & 57 & 3 & 0.3 & 1.6 & 0.1015 & 0.1002 & 0.0013 & 0.1021 & -0.0006 \\
\hline 20 & 4 & 42.5 & 4 & 0.2 & 1.25 & 0.0535 & 0.0494 & 0.0041 & 0.05105 & 0.00245 \\
\hline 21 & 5 & 28 & 5 & 0.1 & 1.6 & 0.024 & 0.0235 & 0.0005 & 0.02488 & -0.00088 \\
\hline 22 & 4 & 42.5 & 4 & 0.2 & 1.25 & 0.05 & 0.0494 & 0.0006 & 0.05105 & -0.00105 \\
\hline 23 & 5 & 57 & 5 & 0.1 & 0.9 & 0.0145 & 0.0166 & -0.0021 & 0.01147 & 0.00303 \\
\hline 24 & 5 & 28 & 3 & 0.3 & 1.6 & 0.12 & 0.1184 & 0.0016 & 0.1032 & 0.0168 \\
\hline 25 & 4 & 42.5 & 4 & 0.1 & 1.25 & 0.019 & 0.0192 & -0.0002 & 0.0113 & 0.0077 \\
\hline 26 & 4 & 42.5 & 3 & 0.2 & 1.25 & 0.0535 & 0.0581 & -0.0046 & 0.04538 & 0.00812 \\
\hline 27 & 4 & 57 & 4 & 0.2 & 1.25 & 0.0515 & 0.0483 & 0.0032 & 0.05488 & -0.00338 \\
\hline 28 & 5 & 57 & 3 & 0.3 & 0.9 & 0.0135 & 0.0145 & -0.001 & 0.0174 & -0.0039 \\
\hline 29 & 5 & 28 & 5 & 0.3 & 0.9 & 0.0075 & 0.0079 & -0.0004 & 0.00699 & 0.00051 \\
\hline 30 & 4 & 42.5 & 4 & 0.3 & 1.25 & 0.0525 & 0.056 & -0.0035 & 0.04492 & 0.00758 \\
\hline 31 & 5 & 42.5 & 4 & 0.2 & 1.25 & 0.051 & 0.0488 & 0.0022 & 0.05792 & -0.00692 \\
\hline 32 & 4 & 42.5 & 4 & 0.2 & 1.25 & 0.0535 & 0.0494 & 0.0041 & 0.05105 & 0.00245 \\
\hline
\end{tabular}




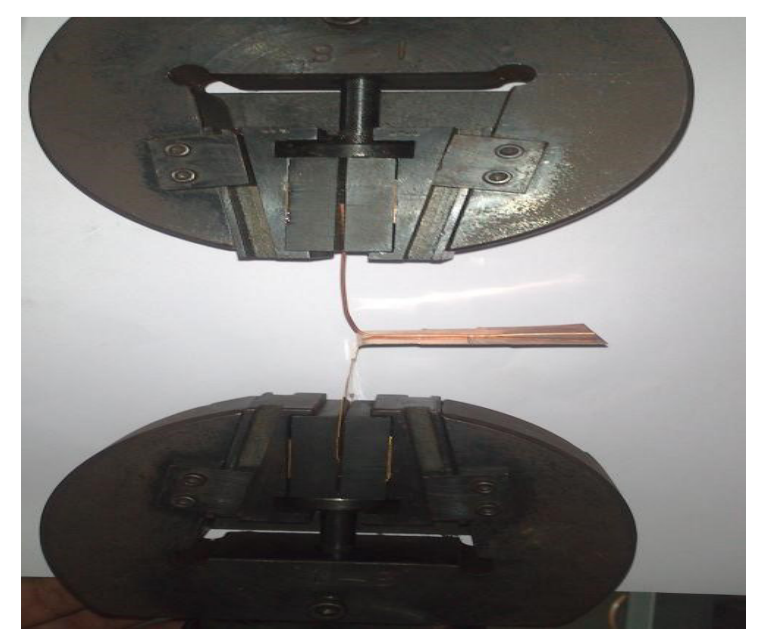

Figure 5 T-peel specimen held in Tensile testing machine

\section{Development of Mathematical model}

Based on the design matrix, experiments are conducted and the results were observed. Using these values an empirical relationship (Equation 1) was found using MINITAB 16.0 Software. The experimental T-peel load for weld joint specimen is presented in Table 2. The second order regression equation for the T-peel load is developed as a function of factors such as weld pressure (bar), amplitude $(\mu \mathrm{m})$, weld time $(\mathrm{sec})$, sheet thickness $(\mathrm{mm})$ and wire diameter $(\mathrm{mm})$.

\section{Predicted T-peel load}

The mathematical model for predicting the T-peel load is given below. This equation helps in predicting the T-peel load values.

$\mathrm{T}$-peel load $=$

$$
\begin{aligned}
& 0.0480078 \mathrm{X}_{1}+0.0018441 \mathrm{X} 2+ \\
& 0.0022117 \mathrm{X}_{3}+0.395398 \mathrm{X}_{4}+ \\
& 0.203443 \mathrm{X}_{5}-0.00101 \mathrm{X}_{1}^{2}+ \\
& 0.00001 \mathrm{X}_{2}^{2}+0.00449 \mathrm{X}_{3}{ }^{2}- \\
& 1.17629 \mathrm{X}_{4}{ }^{2}-0.06949 \mathrm{X}_{5}{ }^{2}- \\
& 0.00028 \mathrm{X}_{1} \mathrm{X}_{2}-0.00441 \mathrm{X}_{1} \mathrm{X}_{3}- \\
& 0.03844 \mathrm{X}_{1} \mathrm{X}_{4}-0.00170 * \mathrm{X}_{1} \mathrm{X}_{5}- \\
& 0.00009 \mathrm{X}_{2} \mathrm{X}_{3}-0.00213 * \mathrm{X}_{2} \mathrm{X}_{4}- \\
& 0.00076 \mathrm{X}_{2} \mathrm{X}_{5}-0.04406 \mathrm{X}_{3} \mathrm{X}_{4}- \\
& 0.00973 \mathrm{X}_{3} \mathrm{X}_{5}+0.54375 \mathrm{X}_{4} \mathrm{X}_{5}- \\
& 0.30120
\end{aligned}
$$


The inputs are fed in the mathematical equation for predicting the T-peel load. The values that are predicted using Equation 1 is shown in the Table 2.

\section{Artificial Neural Network (ANN)}

The fundamental purpose of an artificial neural network is to imitate the operation of the human brain or neural system. These are enormous parallel-connecting networks made up of basic computing pieces known as neurons connected by unidirectional interconnected channels known as the connection, which mimics the human brain.

The feed forward back propagation method is the most often utilised approach in this study. This kind has three layers: an input layer, a concealed layer, and an output layer. The input layer is where the problems' inputs are received. The relationship between the input layers is determined and represented in weights in the hidden layer. The problem's output is emitted in the output layer. In the prediction of results, the training of an ANN is critical. The accuracy of the model is primarily determined by the ANN's training. Table 3 shows the network properties of the ANN employed in this study. The network model for T-peel load prediction is often trained in MATLAB..

Table 3 ANN network properties

\begin{tabular}{|l|l|}
\hline Type of network & Feed Forward back propagation \\
\hline Data input & Training input \\
\hline Data target & Training output \\
\hline Function for training & TRAINLM \\
\hline Function for adaptive learning & LEARNGDM \\
\hline Function for performance & MSE \\
\hline No. of layers & 2 \\
\hline No. of neurons & 2 \\
\hline No. of Epochs & 100 \\
\hline
\end{tabular}

The predicted values of T-peel load using the ANN algorithm are shown in the Table 2.

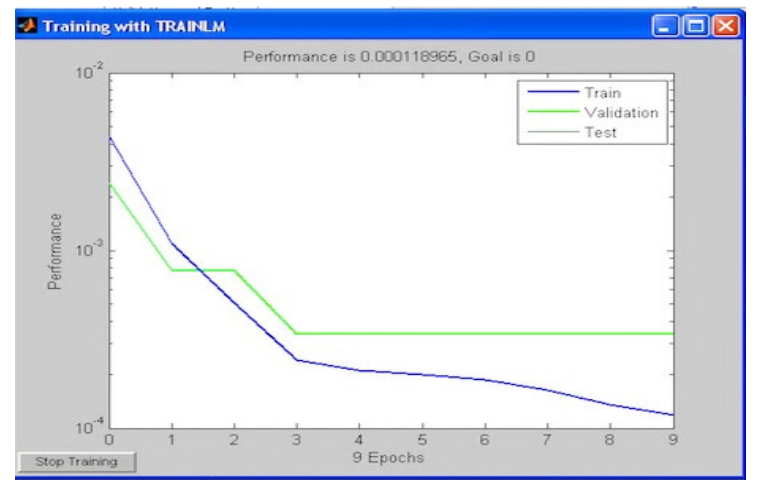

Figure 6 ANN Performance chart 
The error in the performance of the ANN process is found to be 0.000118965 as shown in Figure 6.

\section{ANOVA plot}

ANOVA plot is employed to identify the percentage contribution of each factor. The percentage effect of the various control factors on the T-peel load is shown in Figure 7. The Figure 7 shows that the T-peel load depends on the wire diameter by $50 \%$, sheet by $40 \%$, weld pressure by $6 \%$, weld time by $2 \%$ and amplitude by $1.49 \%$.

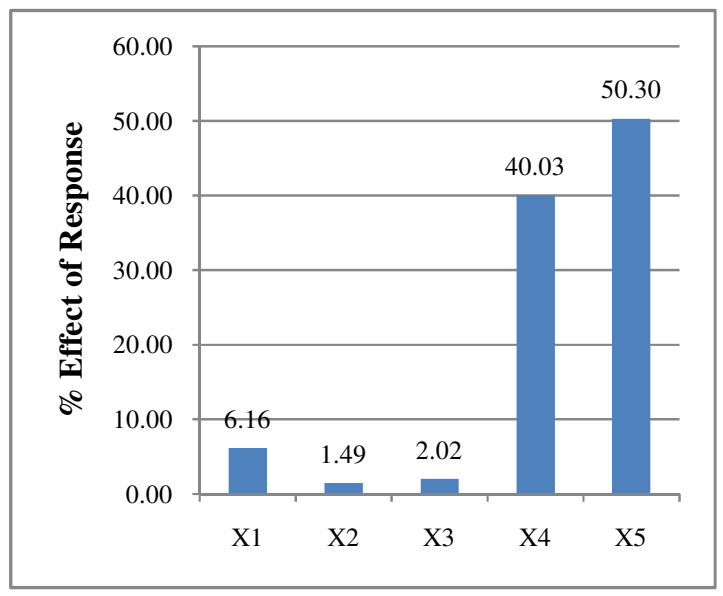

Figure 7 ANOVA Plot

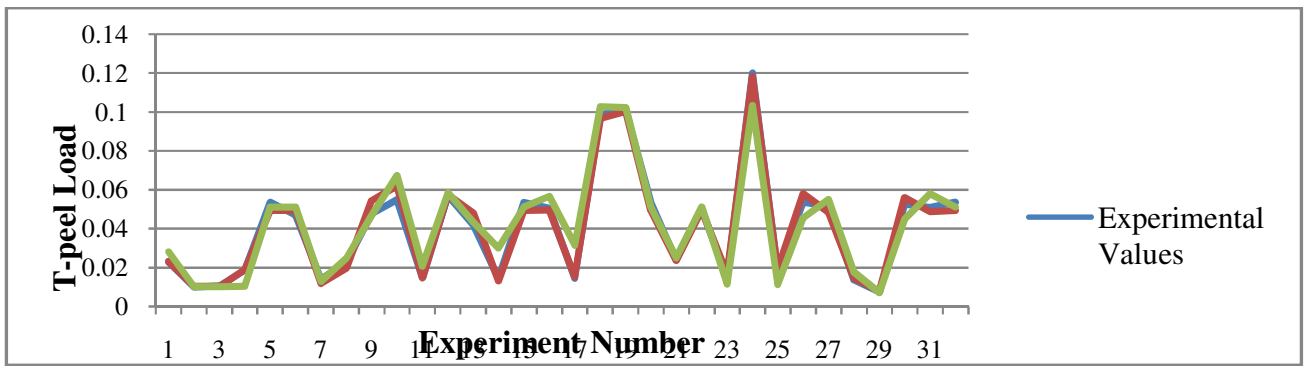

Figure 8 Comparison of experimental values, predicted values (Mathematical model and $\mathrm{ANN}$ ).

From the graph shown in Figure 8 the mathematical model results said to be more promising than the ANN results and the maximum error percentage is found to be $0.5 \%$ for the mathematical model whereas in ANN it is found to be $1.5 \%$. The correlation between the experimental and predicted results was found to be $98.8 \%$ and this clearly explains there is a better correlation between them. 


\section{Conclusions}

Prediction of the weld strength plays a dominant role in many of the industrial process applications. A mathematical model and artificial neural network are being developed to forecast weld strength in terms of T-peel load. Experiments are conducted based on the central composite response surface design matrix. The parameters considered are the weld pressure, amplitude, weld time, sheet thickness and wire diameter. Based on the ANOVA plot it is conclusive that the geometric profiles of the welded specimens play a crucial role in establishing the weld strength apart from process parameters. This study brings out the influence of geometric profiles on the weld strength effectively. The mathematical model is found to predict the weld strength more effectively with $0.3 \%$ error than the artificial neural network with $1.56 \%$ error.

\section{References}

[1] Annoni M, Caboni M, Ultrasonic metal welding of AA6022-T4 lap joints: part 1- Techanogolical characterization and mechanical behavior. Science Technology welds joining, vol. 107, pg. 15, 2011.

[2] Arata N, Journal of Japan Welding Society, 196231 (5) pg. 334-340 and Journal of Japan Welding Society 31 (6) pg. 415-426, 1962.

[3] Chen YC, Bakavos D, GHilinia A, Prangell PB, HAZ development and accelerated post- weld Aging in ultrasonic spot welding aluminium automotive sheet. ACTA Material, vol. 60-2816, pg.28, 2012.

[4] Cochran, W.G., Cox, G.M. Experimental Designs. John Wiley and Sons, New York, 1992.

[5] Elangovan S, Anand K, Prakasan K., Parametric Optimization of Ultrasonic Metal Welding Using Response Surface Methodology and Genetic Algorithm. International Journal of Advanced Manufacturing Technology, 2012.

[6] Hu SJ, Senkara J, Zhang H, Performance characteristics of resistance spot welds in the automotive industry: a structural point of view. In proceedings of IBEC 96 body and engineering. pg. 91-8, 1965.

[7] J.Pradeepkumar and Dr.G.Bhuvanashekara, Prediction of weld bead width using artificial neural network and regression models in laser beam welding, 2010.

[8] Kwon Y, Fischer GW. A novel approach to quantifying tool wear and tool life Measurements for optimal tool Management. International Journal of machining tools and manufacturing. Vol.43, pg.359-368, 2003.

[9] Nepparis EA, Ultrasonic welding of metals. Ultrasonics, pg.7-10,128-35, 1965.

[10] Oraby SE, Hayhurst DR tool life determination based on the measurement of wear and tool force ratio variation. International Journal of Machining tools and Manufacturing, vol.44, pg.1503-1269, 2004.

[11] T.Kuprys ,J.Janutenience, R.Didziookas, strength of copper wire connections welded by ultrasonic. ISSN 1392-1207. MECHNIKA, Nr.3(65), 2007.

[12] U.I.Chang and J.frisch, Optimization of some parameters in ultrasonic metal welding, 2011.

[13] Ultrasonic welding chapter 49 welding hand book, 5th edition American welding society, section III "welding cutting and related processes". 